\title{
'I Just Want It to Be Done, Done, Done!' Food Tracking Apps, Affects, and Agential Capacities
}

\author{
Deborah Lupton \\ News \& Media Research Centre, Faculty of Arts \& Design, University of Canberra, Bruce 2601, Australia; \\ deborah.lupton@canberra.edu.au
}

Received: 25 March 2018; Accepted: 22 May 2018; Published: 23 May 2018

\begin{abstract}
Food-tracking apps constitute a major category of the thousands of food-related apps now available. They are promoted as helping users monitor and measure their food consumption to improve their health or to lose weight. In this article, I present six vignettes drawn from interviews with Australian women about their use and non-use of food-tracking apps. The vignettes provide detailed insights into the experiences of these women and their broader sociocultural and biographical contexts. The analysis is based on feminist materialism theoretical perspectives, seeking to identify the relational connections, affective forces, and agential capacities generated in and through the human-app assemblage. The vignettes reveal that affective forces related to the desire to control and manage the body and conform to norms and ideals about good health and body weight inspire people to try food-tracking apps. However, the agential capacities promised by app developers may not be generated even when people have committed hope and effort in using the app. Frustration, disappointment, the fear of becoming too controlled, and annoyance or guilt evoked by the demands of the app can be barriers to continued and successful use. Sociocultural and biographical contexts and relational connections are also central to the capacities of human-app assemblages. Women's ambivalences about using apps as part of efforts to control their body weight are sited within their struggles to conform to accepted ideals of physical appearance but also their awareness that these struggles may be too limiting of their agency. This analysis, therefore, draws attention to what a body can and cannot do as it comes together with food tracking apps.
\end{abstract}

Keywords: food-tracking apps; vignettes; new materialism; thing-power; agential capacities; affects; embodiment; selfhood

\section{Introduction}

Since the emergence of the smartphone, mobile apps, and wearable devices over the past decade, new opportunities have emerged for people to seek information about food or monitor and manage their food intake. Mobile apps provide a mediated interface in humans' engagements with food. A huge range of apps are now available that relate to various aspects of human food consumption and preparation. These include apps for rating, rating, searching for, and recommending restaurants; making bookings and organising food delivery; conducting grocery price comparisons; checking the ingredients of packaged foods or their ethical/fair trade credentials; planning meals; and providing recipes and cooking instructions. Photo-sharing apps and platforms such as Pinterest and Instagram allow users to take, share, and curate images of food. Food game apps are also available, allowing users to virtually prepare food, run a restaurant, and participate in food-related quizzes.

One major category of food apps relates to the self-monitoring of food consumption and nutrition. These types of apps are promoted to users as ways of helping people achieve and maintain a healthy diet, work towards weight-loss goals, or control a chronic health condition such as diabetes or digestion disorders. Apps in this category include MyFitnessPal, Fitbit, Lose It! Fooducate, FatSecret, 
WeightWatchers, and SparkPeople. It is these food-tracking apps on which I focus in this article, investigating the sociocultural and biographical dimensions of users' experiences. To do so, I draw on findings from the Australian Women and Digital Health Project, in which I used qualitative research methods to engage women in talking about their use of digital health technologies. This project sought to identify the uses and values women attributed to the technologies with which they engaged and explore the biographical and broader sociocultural contexts of their interactions. Numerous participants said that they had used food-tracking apps, including those who were long-term users and others who had tried the apps for a time but did not persist with them.

In what follows, I begin by describing the theoretical background informing my empirical research and providing a review of previous research on food-tracking apps. I then outline details of my project and provide six vignettes drawn from this research as a way of illuminating these women's experiences.

\subsection{Theoretical Background: Feminist Materialism}

The theoretical underpinning of my analysis takes a new materialist perspective on digital technologies, particularly the work of feminist materialism scholars such as Jane Bennett [1,2], Karen Barad [3,4], and Rosi Braidotti [5]. From the feminist materialism perspective, human subjects are not just knowing: they are also sensing, embodied, affective assemblages of matter, thought, and language [5]. Matter (otherwise understood as things, objects, bodies, spaces, and places), Barad argues, is 'an active participant in the world's becoming' [4]. From this perspective, agency is relational and enacted, generated in, with, and through interactions and entanglements of people with technologies as part of more-than-human worlds. Humans come together with nonhumans to configure assemblages that are contingent and emergent, constantly changing as they move through time and space. Together, they generate affective forces and agential capacities that are continually made and reconfigured, responding to these movements, encounters, and actions [4,6,7].

A feminist materialism perspective has not yet been taken up to any great extent to understand humans' encounters with digital technologies such as social media, apps, and wearable devices. In recent work, I have been developing this approach [8-10], which also rests on the key premise that apps and other digital media are sociocultural artefacts that work with and through human users [11]. I contend that when humans are using apps, they are involved in human-app assemblages. The affordances [12] that have been designed into the apps-what they invite and allow users to do-and the scripts [13] that are part of these affordances-the assumptions about users and what they will do with the apps-work with the human users to generate agential capacities and relational and affective forces. These capacities and forces are part of the lived experience of app use: whether an app is experienced as useful, enjoyable, or easy to use; how well it is incorporated into everyday routines; and for how long it is used. Alternatively, agential capacities can be closed off if an app's affordances and scripts do not integrate well with the human user's expectations, experiences, and social and embodied contexts, or if the affective forces that are generated are constraining rather than enabling. In essence, an app is not a discrete technological object with its own capacities: it is animated only when in-use with humans.

The constantly changing nature of the flows of personal data generated from using self-tracking apps is an important feature of this theoretical position [10,14]. New materialist analysis has been criticised for sometimes lacking direct attention to power relations and social inequalities [15]. In response, it has been argued that analysis should be attuned to the micropolitics of power as enabling and vitalising, as well as constraining $[5,16]$. It is here that identifying the capacities and forces generated with and through technologies like apps is important. Drawing on the vital materialism scholarship of Jane Bennett [1,7,17], the term 'thing-power' can be used to describe these capacities and forces. The concept of thing-power acknowledges the potential vitality and vibrancy of human-nonhuman assemblages, including the personal data that are often generated with and through apps such as those used for food-tracking. 
App thing-power begins with the developers' imagined uses of the app and the way it is presented and promoted on forums such as the app stores and industry blogs, or government sites such as the UK's National Health Service Apps Library. Certain promissory narratives [18] are articulated on these sites, in which apps are portrayed in often hyperbolic ways as routes to better health, the amelioration of illness and disease [11], and in the case of food-tracking apps, better management of body weight, nutrition, or chronic illness. Health-related apps, therefore, may be considered objects that are invested with hope and desire related to idealised embodiment [11,14].

The developers' imagined uses of apps may or may not be enacted in the everyday practices of people who have downloaded them. Indeed, in a very crowded and competitive market-place, the vast majority of apps languish in the apps stores. Even if they are downloaded to phones or tablet computers, they are rarely, if ever, used. For example, only 14\% of app users from Australia are still using an app seven days after first installing it on their devices: and figures from other western countries are similar [19]. Interesting questions, therefore, concern how it is that human-app assemblages become invested with thing-power to the point that they become an important part of everyday lives and come to play key roles in enactments and experiences of embodiment, selfhood, and social relations.

\subsection{Previous Research on Food-Tracking Apps}

Previous research on food-tracking apps has been conducted from a number of different perspectives and disciplines, including survey-based research identifying broad trends in use, studies interested in the medical and public health implications, human-computer interaction (HCI) studies focusing on design aspects and user experiences, and qualitative social research interested in the sociocultural dimensions of app use.

A number of survey-based studies have shown that nutrition and weight-loss apps, along with fitness tracking apps, are the most popular among those who use health apps [20-23]. A Nielsen market research report on Americans' use of wearable devices for self-tracking found that women are more likely than men to use diet and calorie-counting apps [24]. The medical and public health literature includes studies on nutrition, diabetes management, calorie-counting, or weight-loss apps. Several of these studies have focused on features of food-tracking apps' content such as their accuracy, usability, and accountability [25]; whether they conform to evidence-informed practices [26] or incorporate expert medical or nutritional knowledge [27,28]; or psychological models of behaviour [29]. Another group of studies has directed attention to how food-tracking apps are used, focusing on elements such as whether they contribute to eating disorders [30,31], and their efficacy in weight-loss efforts [32] and diabetes management [33].

HCI researchers have explored aspects such as the design of nutrition logging or weight-loss devices and apps $[34,35]$ and have experimented with innovative ways of monitoring food consumption [36] or promoting mindful eating [37], as well as user experiences of weight-management apps [38]. Psychological models of behaviour are often applied in persuasive design-oriented research directed at food-tracking apps, with an emphasis on how they can be used to nudge users to change their food consumption behaviours. Critical explorations from a third-wave HCI paradigm [39] incorporating sociocultural and political analyses are not as common in this literature. One notable exception is a critical design article by Purpura and colleagues [40], which called attention to the political dimensions and moral values implicit in digital technologies designed for weight-control and other 'healthy' behaviours by imagining future developments in apps and wearables and their implications. A study of women with a history of eating disorders using weight-loss apps by Eikey and Reddy [41] also put forward a more nuanced and socially contextual analysis that emphasised the importance of recognising the dynamic nature of app use.

A small number of studies conducted by sociologists and cultural studies researchers have delved more deeply into the content of these types of digital technologies and how people use them. In my own work, I have adopted a critical sociological perspective to call attention to the ways 
in which self-tracking apps in general work as disciplinary and metricising devices, valorising the importance of self-management of the body. As I have shown, self-tracking apps often draw on the ideal of self-knowledge achieved through quantification as a selling point, espousing the ideal of the healthy citizen who takes responsibility for promoting her or his health and wellbeing [14,42,43]. More specifically, the biopedagogical dimensions of food-tracking apps have been explored in previous research. A critical content analysis of one online platform and two apps promoted to children or young people to educate them about nutrition and the calorie content of food (the Nourish Interactive platform and the Smash Your Food and MyFitnessPal apps) demonstrated that they presented food-related education very narrowly as relating only to the nutritional content of food (rather than, for example, its flavour or other pleasurable dimensions) [44]. Fotopoulou and O'Riordan [45] conducted an auto-ethnographical study of Fitbit, identifying how it works as a biopedagogical device by prescribing norms and ideals of behaviour around food consumption and physical activity.

While she focused on online weight-loss platforms rather than apps, Niva's [46] analysis of her interviews with Finnish women who have used these platforms is useful in adopting an approach that draws on the concept of scripts of use. Niva notes that the platforms script slimming as a rationalised and calculative practice, demanding a high level of work on the part of users to achieve their goals. Niva's interviewees referred to these platforms as operating as control devices to help them monitor and then discipline their food consumption, and also as learning devices, helping them learn more about the calorie content of foods. Another study involved interviews with English women and men who used the MyFitnessPal calorie-counting app, focusing on the ways in which they incorporated the app into their mundane routines [47]. The researchers found that these people used the app for the most part to achieve a specific weight-loss goal: mostly to look slimmer, but some people wanted to improve their health. The participants tended to follow the calorie-intake recommendations made by the app without questioning them, treating the app as an authoritative tool. The researchers found that few people used the app beyond its basic functions, and most did not review their data over time.

\section{Materials and Methods}

\subsection{Materials}

Findings from my Australian Women and Digital Health Project build on and extend previous research by incorporating a discussion of people's use of food-tracking apps as part of their biographies, social relationships, and use of other digital health technologies. The Australian Women and Digital Health Project is comprised of two separate studies. A total of 66 women participants across the two studies were involved in either interviews or focus groups about their use of digital health technologies. Study 1 involved face-to-face interviews with three sets of women living in the city of Canberra, totalling 36 participants. Study 2 involved telephone interviews with 30 women living in various locations around Australia.

The same semi-structured interview schedule was used with all participants, incorporating questions about what digital health technologies they used for themselves or on behalf of others such as family members and which they found the most useful or helpful. They were also asked to imagine and describe the health-related technologies they would like to see developed in the future. These questions provided the basis of the interviews and group discussions, but interviewers also probed participants for further comments and explanations of their responses, allowing for free-ranging conversations. Ethics approval to conduct this research was granted by the University of Canberra's human ethics research committee. All participants were given pseudonyms to protect their anonymity.

The research material on which I draw in the present article is derived from Study 1 . The interviews and focus groups in this study were conducted by two research assistants employed on the project. The participants were recruited using the Women's Centre for Health Matter's networks, personal contacts, advertising on relevant Facebook pages (such as those for mothers, people with disabilities, 
and women's fitness and sporting groups in Canberra), and posters in public places around the city. Of the 36 participants in Study 1, 28 identified their ancestry as Anglo-Celtic and eight as Asian. Twenty-two participants reported university-level education, while fourteen had high school or technical qualifications.

\subsection{Analysis}

There is no one 'method' for analysing empirical material that has been generated for new materialism approaches. Indeed, researchers who want to engage with new materialism theory tend to eschew a defined method for empirical analysis. Instead, analysis progresses from a set of questions that guide the analysis and a series of principles that acknowledge that any analysis will always be situated. The issue is not so much what a method 'is' as what it can 'do' [48]. Researchers acknowledge that they are part of a 'research assemblage' $[48,49]$, in which their own embodied and experiential positions and interests contribute to what they choose to research and how their research material is analysed. Analyses can therefore only ever be partial rather than making universal claims. Researchers make a series of 'agential cuts' [3] in deciding what to research and how to present their arguments. They engage in creative imaginings in attempting to map the entanglements, assemblages, dynamics of power, and becomings that are represented in research participants' words and practices $[5,50]$. The key research inquiries that provide inspiration and impetus for new materialism empirical researchers include a focus on identifying what bodies can do [51,52], adopting an analytic that pays attention to the flows of affective forces, relational connections, and micropolitics $[4,16]$ which give vitality and power to assemblages.

All the interviews and group discussions were audiotaped and professionally transcribed. The transcripts were analysed by myself using interpretive thematic analysis. I read through the transcripts repeatedly, drawing on the theoretical literature inspiring the research (outlined earlier) to identify the relational and affective forces and agential capacities that emerged in the women's accounts. In what follows, I provide six vignettes drawn from interviewees in Study 1 who discussed in detail their experiences of using or not using food-tracking apps. These women represent a range of ages (including two women in their 20s, two in their 30s, and two aged in their late 40s to mid-50s). They all described themselves as having Anglo-Celtic ancestry, and five of the six had university-level education. Two of the women had used a food-tracking app for a while and were continuing to use it; three others had tried a food tracking app in the past but given it up by the time of the interview; and one woman had considered using such an app but had decided against it. Three of the women were living with chronic health conditions that they had attempted to manage with food-tracking apps, among other tools. Two others had used these apps for losing weight and to improve their health and fitness. As such, a diversity of reasons for and experiences of use of self-tracking are presented in the vignettes.

\section{Vignettes: Jessica, Megan, Justine, Katrina, Erica, and Bryony}

\subsection{Jessica}

Jessica is 24 years old, and a full-time university student who also holds down a part-time job. Jessica enjoys playing team sports. She uses a Garmin smartwatch to monitor her physical activities and to try to improve her sporting performance. Jessica is also attempting to lose weight, both to improve her physical fitness and her appearance. She has the MyFitnessPal app on her phone for counting calories. She uses the smartwatch and this app together to monitor her energy output and input.

In her interview, Jessica talked about how she has struggled with feelings of loss of control over her food intake. She said that she has experienced times in her life when she has had what she describes as 'an unhealthy relationship with food'. Her weight tends to fluctuate a lot, and she has to work hard to maintain a feeling of control over her food consumption and weight: 
So I don't know if these apps actually work but [using them] gives me a sense of control over what I'm doing and when I lose that sense of control, that's when I'll binge eat and go crazy.

For Jessica, the value of being able to enact these measurements is to closely watch her energy expenditure in relation to her food consumption habits. The affordances of the app in terms of detailed recording are important to her need to establish control over her body. This in turn makes her feel better, both in terms of her state of health and her desire to feel in control:

I think that my need to have a calorie-counting app affects my health in that I know that, if I take in a certain amount of calories, I will lose weight. So for me that's very clear cut. So if I need to lose weight, that's a positive effect ... Like at the end of the day if I'm eating less, feeling lighter, I feel better, better about myself, my digestion's better.

Jessica observed that she finds the notifications she receives from the app to be 'a real motivator':

Like when I get really into, it encourages me. So, it tells you like, once you enter your calories for the day, like you say in five or six weeks, if every day was like today, you could weigh this amount and that's a real motivator. Just keep going and I'll lose those few kilos or whatever.

However, she noted that it is her 'attitudes outside the app' that are the most important as motivators-'the app is just a tool'. Jessica does not see the app as doing all the work of monitoring and controlling her weight, therefore, but rather as a key contributor in generating this agential capacity. This perspective is also evident in Jessica's comments about how long she thinks she will use the app. Jessica said that she has learnt about her body and the types of food she should eat from the app. She has found using MyFitnessPal to be more effective than trying to follow a diet. She sees the app is an initial stage in long-term behaviour change, but not something she will use for a long time. She predicted that after she has used the app for a while, her knowledge about her body and how the food she eats affects it will reach a point whereby she will not need the app anymore, and eating decisions will become part of her embodied knowledge:

So yeah, it does definitely change the way I view [my body] but I also know, I think, that the things I've learned from it are positive. And I think I will get to the stage where like all the knowledge I have about my body and what's in food can hopefully accumulate to a place where I'm in control, probably not calorie counting, just getting into a routine, the things I eat, where it becomes a habit.

For Jessica, the actions of using the app to review her food intake each day and thinking about what she should eat the next day are practices of embodied selfhood and discipline that she hopes will shape lifelong habits so that she no longer needs to use the app or even think too much about her diet.

Despite the value Jessica perceives in using MyFitnessPal, she is aware that some of her friends disapprove of the idea that she should be closely monitoring her calorie intake. She has received comments from others that suggest that this practice is obsessive or narcissistic, or evidence that she has a low opinion of her body size.

I think there's a real stigma about calorie counting. It's like a bad thing and it means like maybe how to lose your self-esteem or you're preoccupied with the way you look or you're not happy within yourself ... So from the outside people are like, don't be silly, you're not fat and you're beautiful and you don't need to worry about any of these things.

These experiences highlight the social context in which app use take place. Other people's reactions can support, or in Jessica's case, discourage, app use. For Jessica, however, her friends' opinions are not enough to influence her to give up using MyFitnessPal, because of the other affective forces and agential capacities that her use generates: feeling lighter, feeling better about herself, better knowledge of her body, better health, and above all, a sense of control. 


\subsection{Megan}

Megan is 48, with children at home, is university educated, and is in the process of setting up her own business. She lives with a chronic medical condition, lipoedema, which causes a build-up of fat cells in the lower body and sometimes the arms, causing them to look swollen and lumpy. Megan notes: "This disease looks like obesity, but it's not. Women with this disease are traditionally just told they're overweight, and they should move more and eat less, and that's absolutely not the case." Megan has found from her own experiences and that of others sharing their stories online that the medical profession tends to be dismissive of this condition. She spends a lot of time online looking for information and participating in support networks on Facebook, including one that she started herself that now has almost 1500 members.

As part of Megan's extensive use of a range of digital tools to search for and generate information about her condition and developing her own protocol for managing it, she tried MyFitnessPal for a few weeks to keep track of her diet. She did not use for long, however, as she experienced technological difficulties:

My mobile phone died, and I had to download all my new apps and start again, and I lost all my data on it, and I couldn't find my password, and I had to create a new account. Oh, it was a real pain. That was really annoying.

Megan again referred to how 'annoying' the app is when she noted that its content and functions were based on an American diet and food brands, meaning that she had to spend more effort finding the brands she uses: "I just found that really annoying, that I would have to trawl through American brands and that sort of thing." A further limitation of MyFitnessPal for Megan is that it is designed to focus mostly on calorie intake, which is not a nutritional element that she is most interested in monitoring: "MyFitnessPal keeps freaking out about calories, but the thing with lipoedema is that calories aren't the issue. It's inflammatory foods."

Despite her frustrations with MyFitnessPal, Megan expressed her interest in being able to find an app that was able to monitor her food consumption and body in the ways that would be more useful and beneficial for her and could help her manage her health condition better. She described her ideal digital health device as follows:

It would track weight measurements. It would be awesome if we could have some technology where you could take a photo of yourself and it could measure different things, and compare to previous photos, like standing in the same spot, like some kind of grid. With this disease, a lot of women, we need to measure regularly. So I go to the physio and I get measured quite regularly. It would be awesome to have something that would help us track all those measurements and where we could basically keep a personal health record. With not just weight, but the other stuff. Something that could help the new people track their macros, so carbs and fats and protein that were specific to this disease. So something that could be tailored, easily, where you can turn off things like calorie alerts, and you can tailor it to your specific macro requirements. Also, if it could just scan Australian foods and upload the information, that would be awesome as well.

Megan's (non)use of the food-tracking app she had tried can be contextualised within the broader biographical and social dimensions of her chronic illness. Finding medical practitioners to lack knowledge about how to best treat lipoedema, she has used online resources to research the disease for herself. Her difficulties with MyFitnessPal stemmed from technological problems with her device, but also with the scripts that were embedded into the app which were designed for users based in the USA who were interested in counting calories rather than other nutritional components of their food. Megan's imaginings of her ideal digital health device involved affordances and scripts that would work much better for her specific needs. 


\subsection{Justine}

Justine is 38 years old and has a high-school education. She is in part-time employment and cares for her two young children. She has a chronic health condition, osteoarthritis, in her spine and hip. Justine has also tried using MyFitnessPal to help in counting calories for weight control to help manage her condition. Additionally, she has used a Pilates app and other workout apps to support her exercise program, seeking to improve her health and physical strength and fitness.

Heavier body weight contributes to Justine's chronic pain, as it places more pressure on her spine and hip. She said that she took up the use of the MyFitnessPal app to 'watch my calories' and set a weight-loss goal for herself. Like Jessica, Justine found this feature useful and motivating. It gave her something to aim towards and the app provided regular notifications that influenced her decisions about food consumption:

In five weeks, you'd set a weight goal; a weight-loss goal or a weight-gain goal I guess, as well. So each day I'd put it in, it would say "If you continue to eat like this you will weigh this amount in four or five weeks' time." That made me think, "Oh okay, I won't eat this fruit."

Justine commented that while the MyFitnessPal app 'is not difficult to use', entering the food consumption data is rather 'fiddly' and time-consuming. With juggling her caring responsibilities for her children with her part-time job, she does not always have the time to enter this information. The design of the app is such that she has do this by midnight, and Justine finds this too restrictive, given the other demands on her time. It seemed to her that the app better suited people who had more time to give to inputting personal data in the way demanded by the app:

Yeah, some days I couldn't even do it until late at night. If I don't do it by midnight I'll lose that day. I won't be able to go back and do a diary or two for the next days. That was restrictive as well. I mean, I know a friend who uses it and they live by it. Maybe they've just got the extra time, whereas I've just got a chaotic life in between work and kids that I don't really have the time-I just want it to be done, done, done!

As she said later in her interview, the demands of her life mean that she is not able to give her own health the priority she should. Using a food-tracking app became yet another demand in a busy life where she is also struggling with her chronic pain condition. As a result of these frustrations, Justine stopped using MyFitnessPal after a while, although she still has it on her phone.

In this context, another kind of app would help her more. When asked to describe her ideal digital health device, Justine imagined an app that could help her manage her condition:

If there was an app on there to help specific to what I'm going through in osteoarthritis that would cover occupational therapy, being able to set realistic goals, lifestyle goals. I'd like to get to the point where I can go away on holiday and do big—not big treks, I'm not talking Everest—but walk from one town to the next.

Like Megan, Justine is not necessarily ready to relinquish the hopes she would like to invest in an app that can help her with her chronic medical condition. It is just that this app has not been invented yet.

\subsection{Katrina}

Katrina is 38 and university educated. She has a part-time job in health services and cares for a young son. Like Justine and Megan, Katrina lives with a chronic condition. In her case, it is ulcerative colitis, a type of inflammatory bowel disease (IBD). This is a long-term condition (she has had it for over ten years) that she attempts to manage with a combination of medication and lifestyle modifications.

Katrina has tried several health apps to manage her condition and improve her general health status. One of these apps was specifically designed for people with IBD, involving users inputting information about their symptoms and monitoring their diet. Katrina said that she had turned 
to the app at a time in which she was feeling very ill and quite desperate to improve her health. The app represented a potential way to manage her condition and gain some understanding of what was happening to her body by helping her track and identify what foods might be contributing to her illness:

At the time I was really sick and I felt like it was giving me some control and it was going to provide me with some information that would help me to recognise things that were triggering reactions-like to foods that I ate and stuff like that ... I guess if it showed me a particular thing I could avoid eating it. And I guess it just made me feel better knowing that eventually there might be some way that I could feel better. I guess it's the ultimate goal when you're sick. It's like you want to get better so it's just like okay, what can I do to get better? Okay, well I can try and monitor my health every day. I can see if there are things that are making me worse.

Despite her hopes, Katrina said that the app was very frustrating to use because 'it kept crashing all the time' and losing her data. She described the app as not 'high quality' and noted that her condition had eventually improved in any case, and she no longer needed to use it. But Katrina commented that if the app had operated more efficiently, she would have liked to have collected enough data about her condition to share with her gastroenterologist:

It would have been quite useful to be able to say to him "Look, I've tracked these things over this amount of time and I can see that when I've done this, this and this, this is when it's worse." It would have been good - rather than me trying to keep track of when I have a reaction and be like, "Okay, what have I done in the last week that it could have caused that?"

In Katrina's account of her experiences with this app, it is clear that it offered a beacon of hope as a personal medical device that could potentially provide some insights into her chronic health condition that she could then use to alleviate it. Her imagined use of the app, therefore, was somewhat different from those of the other women living with chronic health conditions, who tried a food-tracking app as a way to lose weight as part of their health management strategies. While the app Katrina used was specifically designed for people with her medical condition, it still did not meet her needs because of its technological failures. She was no longer looking to apps to help her manage her health, both because her condition had improved and because her experiences with the IBD app had disenchanted her.

\subsection{Erica}

Erica, aged 55, is university educated, and in full-time work as an allied healthcare professional. Her children are now adults, and no longer live at home. For several years, Erica has engaged in efforts to become physically fitter and lose weight in the interests of her general health. She has tried various apps (such as MapMyRun) and wearable devices (Fitbit, Garmin smartwatch) to monitor her physical activity and energy use. Erica now uses a Weight Watchers app as part of her weight-loss efforts, in conjunction with a telephone coaching service also provided by the company.

Erica said that in some ways, the functions offered by the Weight Watcher app are useful and helpful. She finds the Weight Watcher app's ability to use barcodes with supermarket products to scan for calories very helpful, as it means she does not have to manually enter this information. As she noted, however, many other foods must still be entered manually so that her 'points' can be calculated. There is also a closed Facebook group associated with the app, which Erica has joined. While she does not find the group very helpful at the moment for her weight-loss efforts, she commented that accessing it and reading other users' status updates has demonstrated to her that "there's a lot of women out there in far worse circumstances than me. That makes me feel a lot happier about where I'm at."

Erica espoused an ambivalent perspective on the Weight Watchers app. She noted that she only enjoys using it when she is able to conform to the expectations and goals it sets her. In this context, the app works to support and validate her efforts. But the app also demands a lot of effort and attention 
from her for it to work properly. Each day, she is supposed to enter in her food consumption and track her exercise. As she said, 'you have to keep motivated' to continue to enter in the information. Erica commented that another demoralising experience is when she is informed by the app that she is not losing enough weight. The app provides her with a regular indication of where she is located on her 'weight journey': "mine's sadly going up, not down at the moment." Erica said that when she is less vigilant about her weight-loss efforts, she tends to not want to use the app:

When I know everything's going well, I'm doing the exercises I should be doing, I'm eating as I should be doing, I'm keeping on track, I'm losing the weight. Then I feel good ... But I know at the moment, I'm not tracking it because I don't want to.

Erica further commented that she feels that if she is not successfully adhering to her weight-loss regimen, the Weight Watchers app acts as a reproach:

You know, the app's on your phone and it's looking at you, and when I look at the phone, it's there. I can't get away from it, unless I moved it. It's that constant reminder-Erica, you haven't filled in [your details] this week, you've put on weight-that sort of stuff.

Erica also mentioned the human weight-loss coach assigned to her by Weight Watchers, who phones her regularly, as another reminder of what she should be doing to lose weight: "I've got the Weight Watchers woman ringing me tomorrow, so I'm thinking, what excuse have I got?" Both app and human coach, therefore, work as potentially motivating, but sometimes overly demanding agents as part of the Weight Watcher system, calling Erica to account. While this be may exactly what was intended by the designers of the system, Erica does not always appreciate it, particularly when she is feeling guilty about not conforming the scripts expected by the system. These feelings can be antithetical to her weight-loss efforts as she then avoids using the app and makes up excuses to deal with the human coach. As Erica described it, she is currently 'in a funk' with Weight Watchers. She related her feelings about the system to the context of her feelings about her weight-loss efforts in general:

I don't know if it's about the tracking, it's more about the psychology of weight loss and gain, and I suppose it all ties up. Yeah, I do start to feel shitty when I know I'm putting on weight, and it does impact then on how I use [the app].

\subsection{Bryony}

Bryony is 25 years old, university educated, and working part-time. In her interview, she talked about why she had decided not to use a calorie-counting app. She said that she was concerned that such apps do not take into account specific aspects of each user, such as whether the individual was female or male, their age, their metabolism, their general health status, or whether they were on medications such as contraception, which she believes can influence her own tendency to put on weight. Her criticism centres on the scripts of the app that do not take into account the situated contexts in which it may be used across different types of users. Bryony characterised these apps as potential unhelpfully because of these limitations:

If it's too simplified, it's just like this isn't actually going to be too helpful. Like, just one simple number or just a few simple numbers without really considering the wider context of why women are a particular weight, or even hormonal things. Some women may have actual health problems that have caused them to gain weight and where exercise will actually kill them because they've had surgery or something like that. So it's not really helpful there I think. I think it would probably suit a particular person, who was, like, I guess really interested in that without all of those health issues or contraceptive sort of issues. Because the contraception does put a spanner in the works there. It literally did that to me. 
Bryony is not only concerned about the limited scripts of calorie-counting apps and their reductive imagining of potential users, but also their potential to contribute to eating disorders or weight-loss efforts that are too extreme. She expressed her worry about becoming too dependent on or obsessive about using a calorie-counting app. She said that she did not want such an app to exert a major influence in her life. Bryony gave the example of a male friend of hers who had used a calorie-counting app and had lost 'too much' weight. She provided further details about her own bodily experiences, aged 19, when her weight-loss had become too extreme. She described a constellation of lifestyle factors that together contributed to her entering a phase when, in her words, she was 'really, really thin, like dangerously so'. Bryony's explanation for her extreme thinness at that time described factors such as walking a lot to get from home to work, working in a part-time job to support her studies in which she was on her feet all day, being a 'gym junkie' and not eating very much. 'It's like, "Oh, but you look thin!" But it wasn't healthy.'

Bryony went on in her interview to criticise what she saw as the judgemental nature of a calorie-counting app, and the possibility it could make her feel bad about herself and start to become intrusive in her life:

[The app] would be very invasive, I think. Because especially since they're like alright, I might have had like okay, one piece of chocolate or maybe the banana bread I had might be full of calories. But it's still got all these other things that I like. It might have been the only thing I had that day as well. Yeah, I don't know. Because it also would feel like I was being judged too which is why I just don't do these things ... this app thing and this quantified number is going to tell me that I should feel bad about myself. I think that is why I get put off.

Bryony reflected about the relationship between how she feels about using a calorie-counting app and her wider feelings about her body weight, including challenges she experiences in coming to terms with how she should evaluate her health in relation to her diet and body weight:

$M m$, it's like probably a lot of things I've internalised myself. What constitutes a healthy body as well. I guess those definitions of what is actually healthy and who has defined it.

Bryony portrayed calorie-counting apps as contributing to pressures she experiences to engage in self-management and self-discipline of her health and weight. In her view, apps can act as a conduit for moral evaluations:

It's also like they're connected to a sort of moral thing too, that consuming too much of something that might not be good for you, is morally reprehensible.

Like Erica, Bryony was concerned about the intrusive nature of a food-tracking app: its potential agential capacity to dominate her food choices and feelings about her body.

\section{Discussion}

The analysis presented here is novel in bringing together a theoretical perspective-new materialism - that has been little employed in social research on digital media with a vignette-based method of social research. Rather than simply conducting a critique of power relations that presents digital technology users as passively inscribed by a set of imperatives (health, body weight, physical attractiveness, nutrition, and so on), my research adopted an approach inspired by feminist materialism's acknowledgement of the productive and affirmative dimensions of thing-power.

The six vignettes presented revealed some important insights into why and how people use food-tracking apps, and the broader biographical and sociocultural contexts in which they do so. It is important to emphasise again that humans and apps work together in generating human-app assemblages, and that agency is distributed between these actors. When apps are directed at monitoring body activities or functions, or for self-management of medical conditions, they are active participants in performances of embodiment and selfhood. As the women's experiences outlined in the vignettes 
demonstrate, in some cases, food-tracking apps can change the ways in which people think about and comport their bodies, including what types of food they eat and in what quantities, and therefore can contribute to material changes in bodies, such as health and wellbeing status and body size and shape. Apps do not act alone, however. These agential capacities can only be generated in-use with the people who engage with the apps.

As I noted earlier, health-related apps are invested with hope and desire by their developers and promoters concerning ideals of embodiment. The vignettes showed that the food-tracking apps that the women had incorporated into their lives generated a range of affective forces and agential capacities. For Jessica, and also for Justine and Erica, at least for a while, the apps helped them feel as if they had exerted some control over their wayward bodies and appetites. The apps provided information, goals to work towards, and notifications that they found to be motivating, spurring them to continued use. For these women, the apps operated as biopedagogical tools, helping them to learn more about the nutritional components of food and also about their bodies. Being able to closely monitor their food intake and being positioned as accountable to the apps' expectations worked for them as a disciplinary technology. At least for a time, using these apps helped them 'feel better' about themselves, as Jessica put it. Other researchers have found that food-tracking apps and platforms can generate these kinds of forces and capacities [45-47] and they were also evident in other research I have conducted with people engaged in self-tracking [8]. These findings suggest that the thing-power of human-app assemblages goes well beyond their biopedagogical capacities. Previous embodied experiences and feelings resonate as women come together with these apps in ways that can be both empowering and constraining.

The vignettes also revealed that food-tracking app enactments can generate affective forces that are challenging and discomforting. For several women, the apps were experienced as overly demanding, pestering, or even judgemental. Justine found that she did not have enough time to meet the app's demands of entering all her information every day. Erica felt as if her app was reproaching her when she did not use it as the app's scripts demanded. Jessica was challenged by other people's negative responses to her use of a calorie-counting app to manage and achieve weight-loss. The vignettes revealed that people may feel ambivalent themselves about their weight-loss efforts, stemming from their deeply-held preoccupations and anxieties about their body weight and appearance. This was the case for Jessica and Erica and also for Bryony, who had made a conscious choice not to use a calorie-counting app because she did not want to become obsessive about it or be placed in a position of being judged or pestered by the app.

These women's accounts of their experiences and feelings demonstrate that food-tracking app use can be simply one dimension in a long biographical history of struggling with body image and body weight management. These findings build on those of Eikey and Reddy [41] in their study involving the use of food-tracking apps by women living with eating disorders, and demonstrate that it is not only women coping with such struggles who may encounter these feelings. The cultural expectation that people should attempt to monitor their food consumption to achieve specific health and appearance ideals underpinned the women's accounts of their food-tracking app use. Women's bodies have historically been represented as inferior to men's because of normative assumptions about their volatility, lack of self-discipline, and inability to regulate and clearly define the boundaries of their bodies [53]. The fat female body has become an archetypal symbol of this supposed lack of self-regulation [54]. In these discursive contexts, the thing-power of the human-app assemblage, rather than facilitating desired capacities, can become an oppressive force that can contribute to people's decisions to relinquish using an app or simply avoiding using it in the first place. Women's ambivalences about using apps as part of efforts to control their body weight are sited within their struggles to conform to accepted ideals of physical appearance, but also their awareness that these struggles may be too limiting of their agency. The app can be experienced as reifying and intensifying personal experiences and broader discourses and norms that seek to discipline and punish women's bodies and make them feel guilty, inferior, or ashamed. 
The vignettes also highlighted the restrictive nature of the scripts and affordances of the food-tracking apps tried by the women. Apps are designed with certain, often very specific, users in mind. In the case of popular food-tracking apps like MyFitnessPal, this user is an able-bodied person living in the USA, who is primarily interested in using the app to count calories to meet weight-loss goals and has the time and other resources available to ensure that the app's demands for dietary information are met each day. As the women's experiences showed, people who do not meet the scripts associated with the imagined user can become annoyed or frustrated and discontinue the use of the app. Megan, Justine, and Katrina experienced frustration and disappointment when they had invested hope in food-tracking apps to provide a solution to a disabling chronic health condition that they longed to control and improve. Their accounts also revealed how some of the affordances and scripts embedded into the apps they used were not designed well enough to generate the agential capacities that the apps promise to users. As these women's experiences demonstrate, these techno-utopian imaginaries are often not enacted in-use.

These insights build on previous research outlined earlier by identifying how the thing-power of these types of apps can be both animated and closed-off in people's lived experiences of trying them or considering their use. The vignettes highlight the complexity of the conditions in which agential capacities can be generated by the human-app assemblage, and the role of relational connections and affective forces in contributing to app use or non-use. As they demonstrate, an app's thing-power is highly unstable and contingent, and can be both enabling and overly intrusive. This analysis, therefore, draws attention to what a body can and cannot do as it comes together with food tracking apps.

Acknowledgments: The author thanks the Women's Centre for Health Matters for assisting with recruitment, Miranda Bruce and Clare Southerton, who recruited participants and conducted the interviews and focus groups in Study 1, the participants for giving their time to be involved, and the University of Canberra] for providing funding for this research.

Conflicts of Interest: The author declares no conflicts of interest.

\section{References}

1. Bennett, J. A vitalist stopover on the way to a new materialism. In New Materialisms: Ontology, Agency and Politics; Coole, D., Frost, S., Eds.; Duke University Press: Durham, NC, USA, 2010; pp. 47-69.

2. Bennett, J. The Enchantment of Modern Life: Attachments, Crossings, and Ethics; Princeton University Press: Princeton, NJ, USA, 2001.

3. Barad, K. Diffracting diffraction: Cutting together-apart. Parallax 2014, 20, 168-187. [CrossRef]

4. Barad, K. Posthumanist performativity: Toward an understanding of how matter comes to matter. Signs 2003, 28, 801-831. [CrossRef]

5. Braidotti, R. A theoretical framework for the critical posthumanities. Theory Cult. Soc. 2018. [CrossRef]

6. Haraway, D. Staying with the Trouble: Making Kin in the Chthulucene; Duke University Press: Durham, NC, USA, 2016.

7. Bennett, J. Vibrant Matter: A Political Ecology of Things; Duke University Press: Durham, NC, USA, 2009.

8. Lupton, D.; Smith, G.J.D. 'A much better person': The agential capacities of self-tracking practices. In Metric Culture: Ontologies of Self-Tracking Practices; Ajana, B., Ed.; Emerald Publishing: London, UK, 2018.

9. Lupton, D. Vitalities and visceralities: Alternative body/food politics in new digital media. In Alternative Food Politics: From the Margins to the Mainstream; Phillipov, M., Kirkwood, K., Eds.; Routledge: London, UK, 2018.

10. Lupton, D. Wearable devices: Sociotechnical imaginaries and agential capacities. In Embodied Technology: Wearables, Implantables, Embeddables, Ingestibles; Pedersen, I., Iliadis, A., Eds.; The MIT Press: Cambridge, MA, USA, 2018.

11. Lupton, D. Apps as artefacts: Towards a critical perspective on mobile health and medical apps. Societies 2014, 4, 606-622. [CrossRef]

12. Davis, J.L.; Chouinard, J.B. Theorizing affordances: From request to refuse. Bull. Sci. Technol. Soc. 2016, 36, 241-248. [CrossRef]

13. Akrich, M. The de-scription of technical objects. In Shaping Technology/Building Society: Studies in Sociotechnical Change; Bijker, W., Law, J., Eds.; MIT Press: Cambridge, MA, USA, 1992; pp. 205-224. 
14. Lupton, D. The Quantified Self: A Sociology of Self-Tracking; Polity Press: Cambridge, UK, 2016.

15. Gerrard, J.; Rudolph, S.; Sriprakash, A. The politics of post-qualitative inquiry: History and power. Qual. Inq. 2017, 23, 384-394. [CrossRef]

16. Alldred, P.; Fox, N.J. Young bodies, power and resistance: A new materialist perspective. J. Youth Stud. 2017, 20, 1161-1175. [CrossRef]

17. Bennett, J. The force of things: Steps toward an ecology of matter. Political Theory 2004, 32, 347-372. [CrossRef]

18. Stephens, N.; Ruivenkamp, M. Promise and ontological ambiguity in the in vitro meat imagescape: From laboratory myotubes to the cultured burger. Sci. Cult. 2016, 25, 327-355. [CrossRef] [PubMed]

19. Johnston, R. Australians Only Use Most Apps for Two Weeks, Tops. 2016. Available online: https://www. gizmodo.com.au/2016/05/australians-only-use-most-apps-for-two-weeks-tops / (accessed on 13 March 2018).

20. Fox, S.; Duggan, M. Tracking for Health; Pew Research Center: Washington, DC, USA, 2013.

21. Krebs, P.; Duncan, D. Health app use among us mobile phone users: A national survey. J. Med. Internet Res. 2015, 3, e101.

22. Accenture Consulting. Accenture 2016 Consumer Survey on Patient Engagement; Accenture Consulting, 2016. Available online: https://www.accenture.com/t20160629T045303_w_/us-en/_acnmedia/PDF-6/ Accenture-Patients-Want-A-Heavy-Dose-of-Digital-Research.pdf (accessed on 25 March 2018).

23. IMS Institute for Healthcare Informatics. Patient Adoption of mHealth: Use, Evidence and Remaining Barriers to Mainstream Acceptance; IMS Institute for Healthcare Informatics: Parsipanny, NJ, USA, 2015.

24. Nielsen, C. Hacking Health: How Consumers Use Smartphones and Wearable Tech to Track Their Health. 2014. Available online: http:/ /www.nielsen.com/us/en/newswire/2014/hacking-health-how-consumersuse-smartphones-and-wearable-tech-to-track-their-health.html (accessed on 2 March 2018).

25. Chen, J.; Cade, J.E.; Allman-Farinelli, M. The Most Popular Smartphone Apps for Weight Loss: A Quality Assessment. JMIR mHealth uHealth 2015, 3. Available online: http://mhealth.jmir.org/2015/4/e104/ (accessed on 2 March 2018). [CrossRef] [PubMed]

26. Breton, E.R.; Fuemmeler, B.F.; Abroms, L.C. Weight loss-There is an app for that! But does it adhere to evidence-informed practices? Transl. Behav. Med. 2011, 1, 523-529. [CrossRef] [PubMed]

27. Nikolaou, C.K.; Lean, M. Mobile applications for obesity and weight management: Current market characteristics. Int. J. Obes. 2017, 41, 200. [CrossRef] [PubMed]

28. Flaherty, S.-J.; McCarthy, M.; Collins, A.; McAuliffe, F. Can existing mobile apps support healthier food purchasing behaviour? Content analysis of nutrition content, behaviour change theory and user quality integration. Public Health Nutr. 2018, 21, 288-298. [CrossRef] [PubMed]

29. Davis, S.F.; Ellsworth, M.A.; Payne, H.E.; Hall, S.M.; West, J.H.; Nordhagen, A.L. Health Behavior Theory in Popular Calorie Counting Apps: A Content Analysis. JMIR $m$ Health uHealth 2016, 4. Available online: http:/ / mhealth.jmir.org/2016/1/e19/ (accessed on 30 March 2018). [CrossRef] [PubMed]

30. Simpson, C.C.; Mazzeo, S.E. Calorie counting and fitness tracking technology: Associations with eating disorder symptomatology. Eat. Behav. 2017, 26, 89-92. [CrossRef] [PubMed]

31. Levinson, C.A.; Fewell, L.; Brosof, L.C. My Fitness Pal calorie tracker usage in the eating disorders. Eat. Behav. 2017, 27, 14-16. [CrossRef] [PubMed]

32. Carter, C.M.; Burley, J.V.; Nykjaer, C.; Cade, E.J. Adherence to a Smartphone Application for Weight Loss Compared to Website and Paper Diary: Pilot Randomized Controlled Trial. J. Med. Internet Res. 2013, 15, e32. Available online: http:/ / www.jmir.org/2013/4/e32/ (accessed on 3 March 2018). [CrossRef] [PubMed]

33. Hood, M.; Wilson, R.; Corsica, J.; Bradley, L.; Chirinos, D.; Vivo, A. What do we know about mobile applications for diabetes self-management? A review of reviews. J. Behav. Med. 2016, 39, 981-994. [CrossRef] [PubMed]

34. Andreas, S.; Simon, F.; Elisabeth, A. Development of a mobile multi-device nutrition logger. In Proceedings of the 2nd ACM SIGCHI International Workshop on Multisensory Approaches to Human-Food Interaction, Glasgow, UK, 13-17 November 2017; ACM: New York, NY, USA, 2017; pp. 5-12.

35. Khatri, A.; Shastri, D.; Tsiamyrtzis, P.; Uyanik, I.; Akleman, E.; Pavlidis, I. Effects of simple personalized goals on the usage of a physical activity app. In Proceedings of the $2016 \mathrm{CHI}$ Conference Extended Abstracts on Human Factors in Computing Systems, San Jose, CA, USA, 7-12 May 2016; ACM: New York, NY, USA, 2016; pp. 2249-2256. 
36. Ye, X.; Chen, G.; Gao, Y.; Wang, H.; Cao, Y. Assisting food journaling with automatic eating detection. In Proceedings of the 2016 CHI Conference Extended Abstracts on Human Factors in Computing Systems, San Jose, CA, USA, 7-12 May 2016; ACM: New York, NY, USA, 2016; pp. 3255-3262.

37. Epstein, D.A.; Cordeiro, F.; Fogarty, J.; Hsieh, H.; Munson, S.A. Crumbs: Lightweight daily food challenges to promote engagement and mindfulness. In Proceedings of the $2016 \mathrm{CHI}$ Conference on Human Factors in Computing Systems, San Jose, CA, USA, 7-12 May 2016; ACM: New York, NY, USA, 2016; pp. 5632-5644.

38. Jill, F.; Brindal, E.; Gilly, H.; Shlomo, B.; Mac, C. Mobile applications to support dietary change: Highlighting the importance of evaluation context. In Proceedings of the CHI '12 Extended Abstracts on Human Factors in Computing Systems, Austin, TX, USA, 5-10 May 2012; ACM: New York, NY, USA, 2012; pp. 1781-1786.

39. Harrison, S.; Sengers, P.; Tatar, D. Making epistemological trouble: Third-paradigm HCI as successor science. Interact. Comput. 2011, 23, 385-392. [CrossRef]

40. Purpura, S.; Schwanda, V.; Williams, K.; Stubler, W.; Sengers, P. Fit4life: The design of a persuasive technology promoting healthy behavior and ideal weight. In Proceedings of the SIGCHI Conference on Human Factors in Computing Systems, Vancouver, BC, Canada, 7-11 May 2011; ACM: New York, NY, USA, 2011; pp. $423-432$.

41. Eikey, E.V.; Reddy, M.C. It's definitely been a journey: A qualitative study on how women with eating disorders use weight loss apps. In Proceedings of the 2017 CHI Conference on Human Factors in Computing Systems, Denver, CO, USA, 6-11 May 2017; ACM: New York, NY, USA, 2017; pp. 642-654.

42. Lupton, D. Quantifying the body: Monitoring and measuring health in the age of mhealth technologies. Crit. Public Health 2013, 23, 393-403. [CrossRef]

43. Lupton, D. Quantified sex: A critical analysis of sexual and reproductive self-tracking using apps. Cult. Health Sex. 2015, 17, 440-453. [CrossRef] [PubMed]

44. Gard, M.; Enright, E. Computer says no: An analysis of three digital food education resources. Asia-Pac. J. Health Sport Phys. Educ. 2016, 7, 205-218. [CrossRef]

45. Fotopoulou, A.; O’Riordan, K. Training to self-care: Fitness tracking, biopedagogy and the healthy consumer. Health Sociol. Rev. 2017, 26, 54-68. [CrossRef]

46. Niva, M. Online weight-loss services and a calculative practice of slimming. Health 2017, 21, 409-424. [CrossRef] [PubMed]

47. Didžiokaitè, G.; Saukko, P.; Greiffenhagen, C. The mundane experience of everyday calorie trackers: Beyond the metaphor of quantified self. New Media Soc. 2017, 20, 1470-1487. [CrossRef]

48. Fox, N.J.; Alldred, P. Mixed methods, materialism and the micropolitics of the research-assemblage. Int. J. Soc. Res. Methodol. 2018, 21, 191-204. [CrossRef]

49. Fox, N.J.; Alldred, P. New materialist social inquiry: Designs, methods and the research-assemblage. Int. J. Soc. Res. Methodol. 2015, 18, 399-414. [CrossRef]

50. Hultman, K.; Lenz Taguchi, H. Challenging anthropocentric analysis of visual data: A relational materialist methodological approach to educational research. Int. J. Qual. Stud. Educ. 2010, 23, 525-542. [CrossRef]

51. Fullagar, S. Post-qualitative inquiry and the new materialist turn: Implications for sport, health and physical culture research. Qual. Res. Sport Exerc. Health 2017, 9, 247-257. [CrossRef]

52. Fox, N.J. Personal health technologies, micropolitics and resistance: A new materialist analysis. Health 2017, 21, 136-153. [CrossRef] [PubMed]

53. Grosz, E. Volatile Bodies: Toward a Corporeal Feminism; Allen \& Unwin: Sydney, Australia, 1994.

54. Lupton, D. Fat, 2nd ed.; Routledge: London, UK, 2018.

(C) 2018 by the author. Licensee MDPI, Basel, Switzerland. This article is an open access article distributed under the terms and conditions of the Creative Commons Attribution (CC BY) license (http://creativecommons.org/licenses/by/4.0/). 